\title{
MOTION SIMULATION OF A FINE SHAPED VESSEL AT HIRON POINT IN THE BAY OF BENGAL
}

\author{
Dr. M. Rafiqul Islam¹, Md. Munir Hassan² ${ }^{1}$ and Dr. Md. Sdaiqul Baree ${ }^{3}$
}

\author{
1 Assistant Professor, Department of Naval Architecture \& Marine Engineering, Bangladesh University of \\ Engineering and Technology, Dhaka-1000,Bangladesh, E-mail: rafiqis@name.buet.ac.bd \\ ${ }^{2}$ Commander, Bangladesh Navy, Chittagong, Bangladesh \\ ${ }^{3}$ Professor, Department of Naval Architecture \& Marine Engineering, Bangladesh University of Engineering and \\ Technology, Dhaka-1000, Bangladesh, E-mail: baree@name.buet.ac.bd
}

\begin{abstract}
The hydrodynamic behaviour of a fast fine vessel is of great importance than that of a fuller vessel as the fast fine vessels are engaged for important operations. Moreover with the advent of modern computers, in ship hydrodynamics, 3-D source distribution method is gaining much popularity and normally applied for blocky hull. But in the case of finer hull, examples are rare especially considering forward speed effect. With these views in mind, in the present research work, effort has been given to develop a mathematical model for fine shape vessel to predict and simulate her motions in irregular waves.

A computer program has been developed on the basis of mathematical model and to examine the validity of the developed program, results for hydrodynamic coefficient and motions of a series 60 ship have been compared with Gerristma's experimental results and with the results based on other codes. After validation of the program, simulation of motions of an existing the fine shape ship has been carried out at Hiron point of the Bay of Bengal by utilizing hydrodynamic coefficients and wave exciting forces and moments obtained in regular waves and a new wave spectrum formula based on wave data at the concerned location. On the basis of the results presented, it may be concluded that the developed model based on 3-D distribution technique can be applied for prediction of motion of fine shape ship with forward speed effect. Moreover limitations of operation of the vessel have been demonstrated at various combinations of significant wave heights and speeds.
\end{abstract}

\section{Introduction}

Sea is a grazing ground where conventional marine vehicles, merchant ships, yachts, passenger ships etc. are moving from one place to another. These ships serve a variety of purposes like naval operations, drilling, marine operations, fishing etc. Wave induced motions can hamper the movement of ship; create severe stresses on the structure and problem from operational point of view. Relative vertical motions are important factor that determine loads on cargo and equipment and an important reason for seasickness. So the knowledge of wave-induced motions is important both in design of ships and its operational studies. In general, study of motions are carried out by two-dimensional strip theory, viz., Salvesen (1970), Vugts (1971) and slender body theory by Newman (1978) that were often utilized to calculate the wave forces and its responses on floating bodies. But the theory is inadequate because of the assumption that ships consists of series of transverse segment or strip, flow to and around each strip is two dimensional in nature and no interactions of the flows at adjacent sections etc 
are taken. On the other hand, numerical methods using 3-D source method in ship hydrodynamics account for interaction between steady wave system and the oscillatory effects of ship motions as well as properly account for accurate shape of the vessel. In the last few decades, significant development has been observed on the ship hydrodynamic problem mainly on offshore structures having zero forward speed and in this regard the works of Faltinsen (1975), Hogben (1975), Garison (1978) \& Inoue (1996) can be referred.

But for a floating body including forward speed creates a quite complex situation to obtain the hydrodynamic forces and moments. For the speed dependent situation, the general boundary condition becomes complicated that makes the problem quite complex.

Works on vessels considering forward speed is limited [Inglis (1981), Iwashita (1989), Faltinsen (1991), Islam (2003)] and these research works were carried out taking large panels due to limitation of computing facility. Moreover the hydrodynamic behaviour of a fine fast ship vessel is of great importance than that of a fuller vessel as the fast fine vessels are engaged for important operations. Examples in this respect can be drawn from those of naval vessels; frigates which are fast fine shaped and are engaged for important operations. Again, with the advent of modern computers, in ship hydrodynamics, 3-D source distribution method is gaining much popularity and normally applied for blocky hull. But in the case of finer hull, examples are rare especially considering forward speed effect. Hence the main objective of this research work is to develop a mathematical model based on 3-D source distribution technique using linear wave theory, validate the developed model and to apply it for an existing fine shaped ship for motion simulation. In order to obtain the motion simulation in irregular waves, the hydrodynamic coefficients and wave exciting forces and moments were calculated in finite water depth condition. Utilizing the above results (added mass, damping coefficients and wave exciting forces) the time domain motion simulation of the same vessel was carried out in an irregular sea at Hiron Point of the Bay of Bengal by applying a new wave spectrum formula [Alam (2000)] developed by regression analysis using wave data at the concerned location. It may be noted that for this purpose standard ITTC or ISSC spectrum formulae have not been used as these formulae are recommended when wave data are not available.

\section{Mathematical model}

Two right-hand Cartesian co-ordinate systems, one fixed with respect to the mean position to the body $(\mathrm{X}, \mathrm{Y}, \mathrm{Z})$ and another fixed to the space $\left(X_{0}, Y_{0}, Z_{0}\right)$ have been used. The positive Z-axis is vertically upward. For the fixed co-ordinate system, the positive Z-axis (OZ) passes through the centre of gravity of the body in still water condition; the origin $\mathrm{O}$ in the plane of the undisturbed free surface i.e. in the calm water surface and OXY represents the calm water plane. If the body moves with a mean forward speed $(\bar{U})$, this coordinate system moves with the same speed. The body is normally assumed to have the $\mathrm{X}-\mathrm{Z}$ plane as a plane of symmetry. The translatory displacements in the $\mathrm{X}, \mathrm{Y}$ and $\mathrm{Z}$ directions with respect to the origin are $X_{1}, X_{2}$ and $X_{3}$ respectively so that $X_{1}$ is the surge, $X_{2}$ is the sway and $X_{3}$ is the heave displacement. Furthermore, the angular displacement of the rotational motion about the $\mathrm{X}, \mathrm{Y}$ and $\mathrm{Z}$ axis are $X_{4}, X_{5}$ and $X_{6}$ respectively so that $X_{4}$ is the roll, $X_{5}$ is the pitch and $X_{6}$ is the yaw angle. The coordinate system is shown in Figure: 1.

\section{Governing Equations}

Assuming the amplitude of the motions as well as that of the incident waves are small, and the fluid is inviscid and irrotational, for a three-dimensional arbitrary shaped body traveling at constant forward speed $\bar{U}$, the total velocity potential $\Phi$ can be written as

$\Phi(x, y, z, t)=-\bar{U} x+\phi_{s}+\phi$ 
where, $\phi_{S}=$ steady velocity potential due to mean forward speed of the ship

and

$\phi=\phi_{0} e^{-i \omega_{e} t}+\phi_{7} e^{-i \omega_{e} t}+\sum_{j=1}^{6}-i \omega_{e} \bar{X}{ }_{j} \phi_{j}$

$\phi_{0}=$ incident wave potential

$\phi_{7}=$ diffraction wave potential

$\phi_{j}=$ potential due to motion of the body in j-th mode i.e. radiation wave potentials,

$\bar{X}_{j}=$ motion amplitude of the body in j-th mode,

$\omega_{e}=$ encountering frequency and is defined as

$\omega_{e}=\omega-\frac{\omega^{2} \bar{U}}{g} \cos \chi$

$\omega=$ circular frequency of incident wave

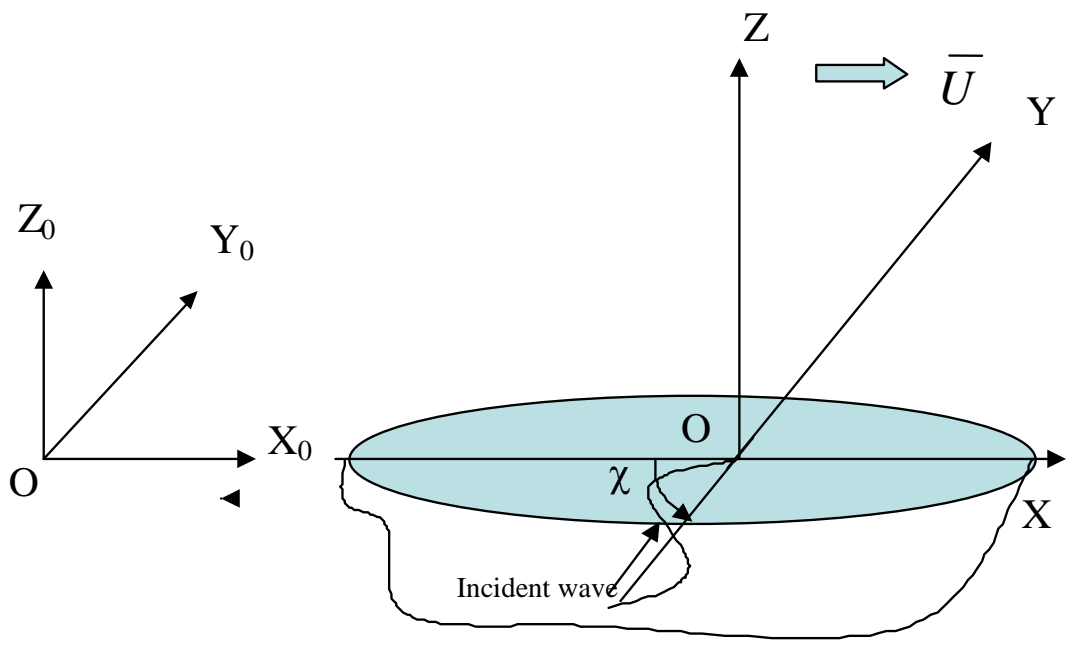

Figure 1: Convention for co-ordinate system

As the present research work has been carried out mainly on a fine shaped small vessel and the characteristic dimension of the ship is relatively small compared to the wave length, the structure creates less obstruction to the propagation of waves and due to finer underwater hull shape, the incident waves also get less scattered. Thus the diffraction potential of the incident waves will be very less in comparison to other potentials due to less scattering of incident waves and can be neglected. Some researchers [viz. Wang (1999)] have used 3D source method for slender bodies with relaxed radiation condition for computing ship motion. So assuming the value of $\phi_{7}$ very small comparing to $\phi_{j}, \phi_{7}$ can be neglected and the velocity potential can be written as: 


$$
\phi=\phi_{0} e^{-i \omega_{e} t}+\sum_{j=1}^{6}-i \omega_{e} \overline{X_{j}} \phi_{j}
$$

The incident wave potential is defined as:

$$
\phi_{0}=\frac{-i g \zeta_{a}}{\omega} \frac{\cosh [k(z+h)]}{\cosh k h} e^{i k(x \cos \chi+y \sin \chi)}
$$

where, $\zeta_{a}=$ incident wave amplitude,

$\chi$ = wave heading angle from $\mathrm{X}$-axis

The differential equation governing the fluid motion follows from the application of the continuity equation, which yields the Laplace equation. The individual potentials are the solutions of the following Laplace equation:

$$
\nabla^{2} \phi=0
$$

On the mean wetted surface area $\mathrm{S}$, the above linear velocity potentials must satisfy this Laplace equation and also the following boundary conditions:

\section{Boundary conditions}

(i) The steady motion potential:

$\bar{W} \cdot n=0$ on $\mathrm{S}$

where $\bar{W} \cdot n=\bar{U} \nabla(\bar{\phi}-x)$ and $\bar{U} \bar{\phi}=\phi_{s}$

(ii) Linearized free surface boundary condition:

$$
\frac{\partial \phi}{\partial z}=\frac{\omega_{e}^{2}}{g} \phi \text { at } Z=0
$$

iii) The boundary conditions on the wetted surface of the floating bodies. Due to linearization, this boundary condition may be applied on the wetted surface of the floating body in their equilibrium position

$$
\frac{\partial \phi}{\partial n}=0 \text { on } S
$$

and

$$
\frac{\partial \phi_{j}}{\partial n}=i \omega_{e} n_{j}+\bar{U}_{j} \text { on } S
$$

In which $n_{j}$ is the direction cosine on the surface of the body in the $\mathrm{j}$-th mode of motion and has the following form: 


$$
\begin{aligned}
& n_{1}=\cos (n, x) \\
& n_{2}=\cos (n, y) \\
& n_{3}=\cos (n, z) \\
& n_{4}=\left(y-y_{G}\right) n_{3}-\left(z-z_{G}\right) n_{2} \\
& n_{5}=\left(z-z_{G}\right) n_{1}-\left(x-x_{G}\right) n_{3} \\
& n_{6}=\left(x-x_{G}\right) n_{2}-\left(y-y_{G}\right) n_{1} \\
& \text { and } m_{1}=m_{2}=m_{3}=m_{4}=0, m_{5}=n_{3}, m_{6}=-n_{2}
\end{aligned}
$$

where $x_{G}, y_{G}$ and $z_{G}$ are the co-ordinate of the centre of gravity of the body and $x, y, z$ are the investigating point on the wetted surface of the body.

In fact, there is no analytical solution for $\phi_{j}$. So the problem needs to be solved by applying one of the numerical technique and in this research work this problem has been solved by 3-D source method. According to 3-D source distribution method, the potentials $\phi_{j}$ can be expressed in terms of wellknown Green functions. As a result, boundary conditions are reduced only on wetted surface of the body. So, the wetted surface is divided into a number of panels to transform integral equations to a system of algebraic equations to determine unknown source density over each panel.

The potential function at some point $\mathrm{P}(x, y, z)$ in the fluid region in terms of surface distribution of sources can be written as:

$$
\phi_{j}(x, y, z)=\frac{1}{4 \pi} \iint_{s} \sigma_{j}(\xi, \eta, \zeta) G(x, y, z, \xi, \eta, \zeta) d s
$$

Where, $(\xi, \eta, \zeta)$ denotes a point $\mathrm{Q}$, on surface $\mathrm{S}$ and $\sigma(\xi, \eta, \zeta)$ denotes the unknown source distribution. The integral is to be carried out over complete immersed surface of the object. The Green function $G$ (source potential) must in order to be valid, satisfy all the boundary conditions of the problem with the exception of the kinematics condition [equation 8, 9 and 10] and have a source like behavior. The particular expression for $\mathrm{G}$ appropriate to the boundary value problems posed is given in two different forms by Wehausen and Laitone [1969]. One of these is the integral form and has the following forms:

$$
G(x, y, z ; \xi, \eta, \zeta)=\frac{1}{R_{1}}-\frac{1}{R_{2}}+\frac{2 g}{\pi} \int_{0}^{r} \int_{0}^{\infty} \frac{h(k, \theta)}{g k-\left(\omega_{e}+\bar{U} k \cos \theta\right)^{2}} d k \cdot d \theta
$$

where,

$$
\begin{aligned}
& h(k, \theta)=k \cdot e^{k\left\{z_{P}+z_{Q}+i\left(x_{P}-x_{Q}\right) \cos \theta\right\}} \cdot \cos \left\{k\left(y_{P}-y_{Q}\right) \sin \theta\right\} \\
& R_{j}^{2}=\left(x_{P}-x_{Q}\right)^{2}+\left(y_{P}-y_{Q}\right)^{2}+\left(z_{P}+(-1)^{j} z_{Q}\right)^{2} \text { for } \mathrm{j}=1,2
\end{aligned}
$$

The solution to the boundary value problem is given by equation (11) satisfied all the boundary conditions since $\mathrm{G}$ itself satisfies these conditions. 
After getting the velocity potentials with the help of numerical calculation of the source density and velocity potential done on the basis of Green function, the hydrodynamic pressure at any point on the body can be obtained from the linearized Bernoulli's equation and can be written as:

$$
\frac{\partial \Phi}{\partial t}+\frac{1}{2}(\nabla \Phi)^{2}+\frac{P}{\rho}+g z=0
$$

Now after putting the value of $\Phi$ in the equation (13), the following expression is obtained,

$$
-\frac{P}{\rho}=-i \omega_{e} \phi+\frac{1}{2}\left\{\nabla\left(-\bar{U} x+\phi_{s}\right)\right\}^{2}+\nabla\left(-\bar{U} x+\phi_{s}\right) \cdot \nabla \phi+\frac{1}{2}(\nabla \phi)^{2}+g z
$$

By neglecting the higher order terms, we can write

$$
P=\rho\left(\overline{\frac{U}{2}} \frac{\partial \phi_{s}}{\partial x}-g z\right)+\rho\left(i \omega_{e} \phi+\bar{U} \frac{\partial \phi}{\partial x}\right)
$$

The first part of equation (15) is associated with the hydrostatic and steady forces, and for simplicity neglecting this part and by taking the dynamic fluid pressure part, the pressure expression becomes as given below. In this respect work of Makino (1997) can be refereed.

$$
P=\rho\left(i \varpi_{e} \phi+\bar{U} \frac{\partial \phi}{\partial x}\right)
$$

So the first order wave exciting forces or moments and oscillatory forces and moments caused by the dynamic fluid pressure acting on the body can be obtained from the following integrals:

$$
\begin{aligned}
& F_{k} e^{-i \omega_{e} t}=\int_{s}\left\{\phi_{0}-i \frac{\bar{U}}{\omega_{e}}\left(\frac{\partial \phi_{0}}{\partial x}\right)\right\} n_{k} d s \\
& F_{k j} \cdot e^{i \omega_{e} t}=-\rho e^{-i \omega_{e} t} \int_{s}\left\{\omega_{e}{ }^{2} \bar{X}_{j} \phi_{j}-i \omega_{e} \bar{X}_{j} \bar{U} \frac{\partial \phi_{j}}{\partial x}\right\} \cdot n_{k} \cdot d s
\end{aligned}
$$

where,

$F_{\mathrm{k}}$ denotes the $k$-th component of wave exciting forces or moments

$F_{k j}$ denotes the $k$-th component of force arising from the $j$-th component of motion of the body.

Moreover, it is customary to decompose the hydrodynamic forces resulting from motion of the bodies into components in phase with the acceleration and velocity of the rigid body motions. These yield the added mass $a_{k j}$ and damping coefficients $b_{k j}$ respectively. These coefficients can be expressed from equation as:

$$
\begin{aligned}
& a_{k j}=-\rho \cdot \operatorname{Re}\left[\int_{s}\left(\phi_{j}+\frac{\bar{U}}{\omega_{e}} \frac{\partial \phi_{j}}{\partial x}\right) \cdot n_{k} \cdot d s\right] \\
& b_{k j}=-\rho \omega_{e} \cdot \operatorname{Im}\left[\int_{s}\left(\phi_{j}+\frac{\bar{U}}{\omega_{e}} \frac{\partial \phi_{j}}{\partial x}\right) \cdot n_{k} \cdot d s\right]
\end{aligned}
$$




\section{Equation of Motion in Time Domain}

The approach to the hydrodynamics of a floating body has been discussed in the previous section based on a description of fluid and body motion in frequency domain. Such description is quite adequate provided that the system is linear and the mean position of the floating structure does not change. But as soon as the non-linear load displacement characteristics are considered, a time domain description is required.

For time domain motion analysis of a floating structure, motion equation can be derived on the basis of the equation proposed by Cummins (1962), where frequency dependency of hydrodynamic reaction forces is taken into account by means of convolution integral. The equation of motion in time domain can be written as:

$\sum_{j=1}^{6}\left(M_{k j}+m_{k j}\right) \ddot{X}_{j}+\int_{-\infty}^{t} R_{k j}(t-\tau) \dot{X}_{j} d \tau+B_{n}\left|\dot{X}_{j}\right| \dot{X}_{j}+C X_{j}=F_{k}$

Where,

$M_{k j}=$ inertia matrix of $\mathrm{kj}$,

$m_{k j}=$ frequency independent added mass matrix of $\mathrm{kj}$,

$R_{k j}=$ retardation function matrix of $\mathrm{kj}$,

$B_{n}=$ non linear damping coefficient matrix of $\mathrm{kj}$,

$C$ = restoring coefficient matrix of $\mathrm{kj}$,

$F_{k}$ = wave exciting force vector in k-mode,

Components of $m_{k j}$ and $R_{k j}$ matrices have the following forms:

$$
\begin{aligned}
& m_{k j}=a_{k j}\left(\omega^{*}\right)+\frac{1}{\omega^{*}} \int_{0}^{\infty} R_{k j}(t) \sin \left(\omega^{*} t\right) d t \\
& R_{k j}(t)=\frac{2}{\pi} \int_{0}^{\infty} b_{k j}(\omega) \cos (\omega t) d \omega
\end{aligned}
$$

Here $a_{k j}$ and $b_{k j}$ are frequency dependent added mass and damping coefficients matrices respectively ( $\mathrm{k}$ and $\mathrm{j}$ take values from 1 to 6 ) and $\omega^{*}$ is the constant frequency which can be chosen arbitrarily. The advantages of describing the hydrodynamic forces due to added mass and damping effects using retardation functions lies in the fact that arbitrary motions can be accommodated correctly, irrespective of the motions of the structure. Using above definition, the equation of motion showing only the linear damping term at $\mathrm{n}$-th time step $(\mathrm{t}=\mathrm{n} \Delta t)$ can be rewritten in the following form Islam (2001):

$$
\sum_{j=1}^{6}\left(M_{k j}+m_{k j}\right) \ddot{X}_{j}+\Delta t R_{k j}(p=0) \dot{X}_{j}+C X_{j}=F_{k}-\sum_{p=1}^{n} R_{k j}(p) \dot{X}_{j}(n-p) \Delta t
$$

The above equation can be solved by one of the numerical integration techniques in each time step. For the present study Newmark-Wilson [Garrison (1978)] method has been applied to solve the equation. 


\section{Wave Profile used in Time Domain Simulation}

For multidirectional irregular waves, the profile can be written as sum of component harmonic waves as follows:

$\varsigma(t: x, y)=\sum_{i} a_{i} \cos \left(\omega_{i} t-\kappa_{i} x \cos \chi_{i}-\kappa_{i} y \sin \chi_{i}+\varepsilon_{i}\right)$

where, $a_{i}$ is the wave amplitude of a component wave of attack angle $\chi_{i}$, frequency $\omega_{i}$, wave number $\kappa_{i}$ and $\varepsilon_{i}$ is in general a uniform distributed random phases. Then the wave elevation of equation (25) at the centre of co-ordinates becomes:

$$
\varsigma(t)=\sum_{i} a_{i} \cos \left(\omega_{i} t+\varepsilon_{i}\right)=\operatorname{Re} \sum_{i} A_{i} e^{i \omega_{i} t}
$$

The wave amplitude $A_{i}$ can be expressed by a wave spectrum $S(\omega)$. and can be written as:

$$
\frac{1}{2} A_{i}^{2}=S(\omega) \Delta \omega
$$

Where,

$\Delta \omega$ is a constant difference between successive frequencies.

An investigation was carried out in Alam [2000], for analysis and estimation of wave spectra at Hiron Point of the Bay of Bengal by using fast Fourier Transform. The wave data that was used for computation had been collected from mathematical model study and progress report of wave measurement of the concerned location by Danish Hydraulic Institute in collaboration with Bangladesh University of Engineering and Technology (BUET), (DHI, 1994). It has been shown from the regression analysis that the following formula may be applied for estimation of spectral density at Hiron Point of the Bay of Bengal.

$$
S(\omega)=A \omega^{-5} \cdot e^{-\frac{B}{\omega^{4}}}
$$

Where, $A=0.061$ and $B=\frac{0.244}{H_{1 / 3}^{2}}$ for Hiron point.

Where, $H_{1 / 3}=$ Significant wave height in $\mathrm{m}$

$\omega=$ Circular frequency in $\mathrm{rad} / \mathrm{sec}$

$S(\omega)=$ wave spectrum

\section{Paneling/Meshing of Ship}

A high-speed fine shaped ship has been taken for investigation, the particulars of which are given in Table 1. Panel methods are the most common techniques used to analyze the linear steady state response in regular waves. To utilize the 3-D source and for numerical computation, the complete wetted surface of the ship selected has been divided in to a number of panels. The full body mesh arrangement is shown in Figure 2.

\section{Validation}

In order to validate the developed program, steps have been taken to calculate the hydrodynamic coefficients and motions of a series 60 ship (Model number: 4210W), in regular wave with constant 
forward speed in frequency domain. The results have been compared with the results experimentally determined by Gerritsma (1960) (taken from PNA, Volume -III, 1988) for the Series 60 parent forms of block coefficients $\mathrm{C}_{\mathrm{B}}=0.60$. The non-dimensional heave added mass $\left(a_{33}^{\prime}=\frac{a_{33}}{\rho \nabla}\right)$ comparison is shown in Figure 3.

Table 1: Principal Particulars of the fine shape vessel

\begin{tabular}{|l|l|}
\hline Length, Maximum (over all) & $58.773 \mathrm{~m}$ \\
\hline Length, at designed water line & $56.00 \mathrm{~m}$ \\
\hline Breadth, max. & $7.20 \mathrm{~m}$ \\
\hline Breadth at the designed water line & $6.90 \mathrm{~m}$ \\
\hline Depth, moulded, at amidships at upper deck & 4.300 \\
\hline Depth, moulded, at stem & $6.00 \mathrm{~m}$ \\
\hline Depth, moulded, at stern & $4.20 \mathrm{~m}$ \\
\hline Draft, at full load displacement & $2.258 \mathrm{~m}$ \\
\hline Displacement, at full load & 392.08 tons \\
\hline Block coefficient & 0.439 \\
\hline Transverse Metacentric height & $0.73 \mathrm{~m}$ \\
\hline Longitudinal Metacentric height & 139.5 \\
\hline Draft up to propeller tip (one blade vertically upward) & $1.10 \mathrm{~m}$ \\
\hline
\end{tabular}

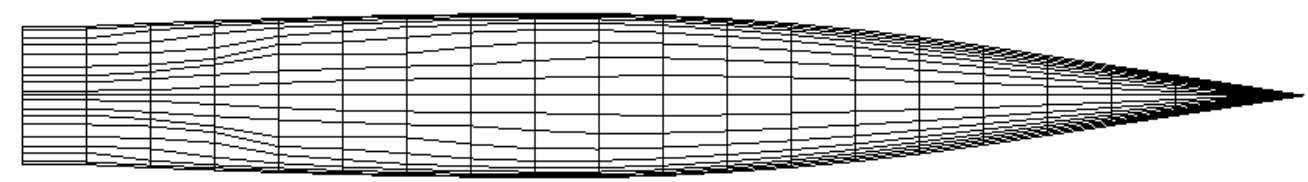

Figure 2: Full body mesh arrangement of fine ship

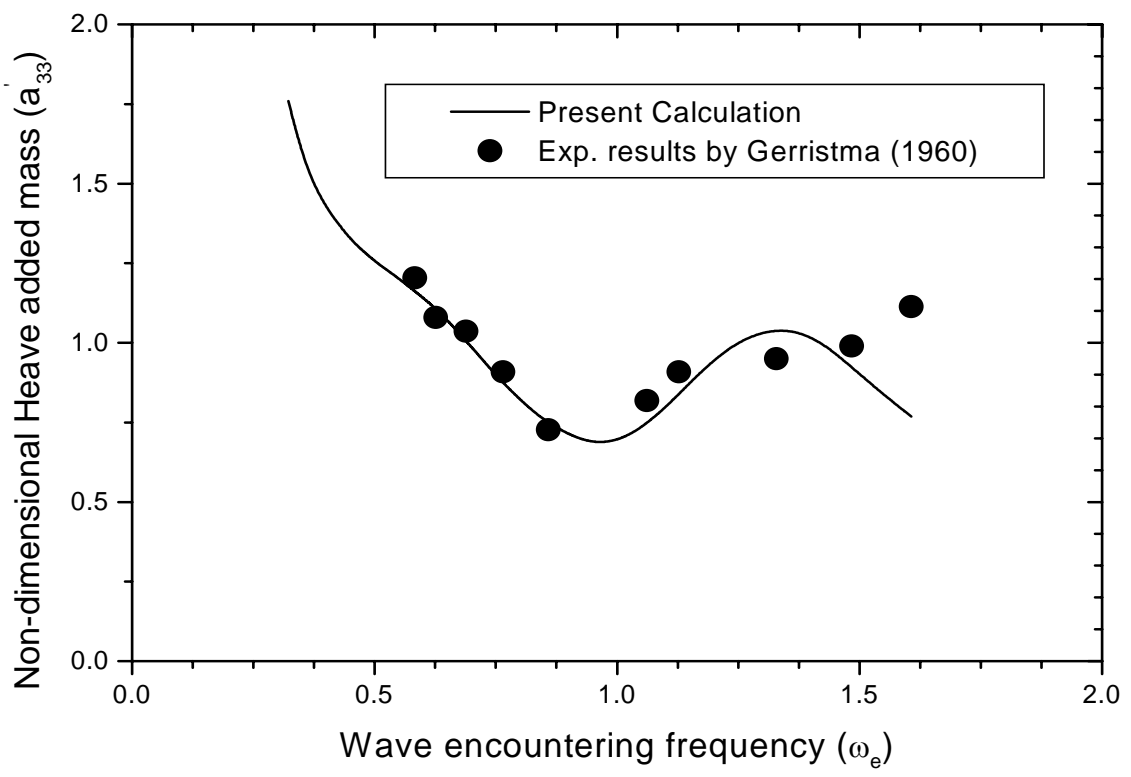

Figure 3: Comparison of Heave Added mass $(\mathrm{Fn}=0.25)$ 
The comparative results show the satisfactory agreement between the computed result and Gerritsma's model test result of added mass. Gerritsma also experimentally investigated the pitch and heave motions with forward speed effect in head sea condition of Series 60 ships parent forms. The motions obtained by Gerritsma (1960) (taken from PNA, Volume III, 1988) are plotted against different wave encountering frequency and compared with the computed motions in frequency domain in regular head sea condition of same Series 60 ship by 3-D source method and is shown in Figure 4.

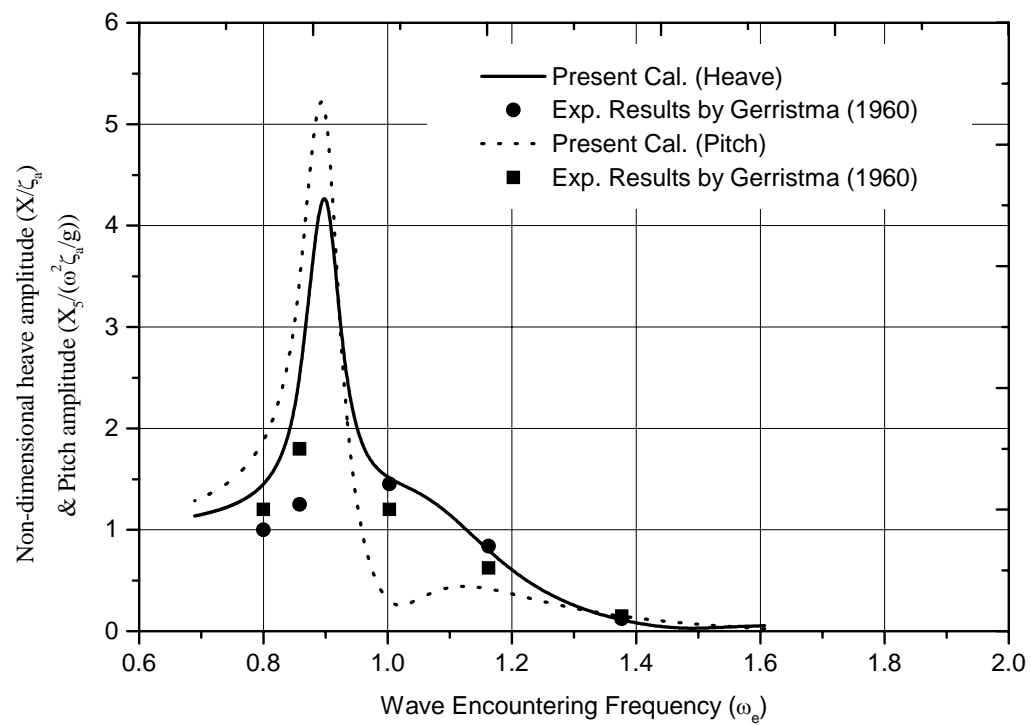

Figure 4: Comparison of experimental and calculated results of Heave response $\left(F_{n}=0.25\right.$, head sea (condition)

By analyzing the heave and pitch motions, it is found that the agreement is very good between Gerritsma's results and computed results within the range of encountering frequency 1.0 and above and have satisfactory similarity in shape and magnitude at encountering frequency below 0.90 . Computed results show a sudden jump at frequency range 0.90 to 1.0 but within this range experimental results are not available, however the overall shape of the curve shows good agreement. This sudden jump may be due to natural heave \& pitch period of the vessel at resonance.

It may be recalled that in process of computation, diffraction potential has been discarded. In order to have a justification for this, computations have been made for heave motion of a series 60 ships with block coefficient of 0.6 considering with and without diffraction effect. The results are shown in Figure 5.

It is seen from the figure that the results are very close to each other. In order to make a comparison of the results obtained by present method with other code, results have been shown in Figure 6 for pitch motion for a series 60 ship with block co-efficient of 0.70 at Froude No. 0.2 with that of English and Price (1981) who have made 3-D computation for the same ship. It is seen from the figure that results are also supportable to each other.

\section{Results of Time Domain Motion Simulation at different ship speed}

The simulation of the selected vessel is carried out at the Hiron point of the Bay of Bengal for head sea condition using the spectrum developed on the basis of wave data as mentioned before.

The vertical displacement at stern due to the combined effect of heave and pitch motion and wave elevation at stern i.e. the relative motion of stern with respect to wave surface are calculated and plotted in figures 7 to 12. Their combined effects are added according to sign convention (figure 13) to get total vertical displacement of a point relative to wave surface at stern position, which was initially on 
the load water line in calm water condition. A typical example of relative vertical displacement at stern using figures $9,10 \& 12$ is given in Table 2 .

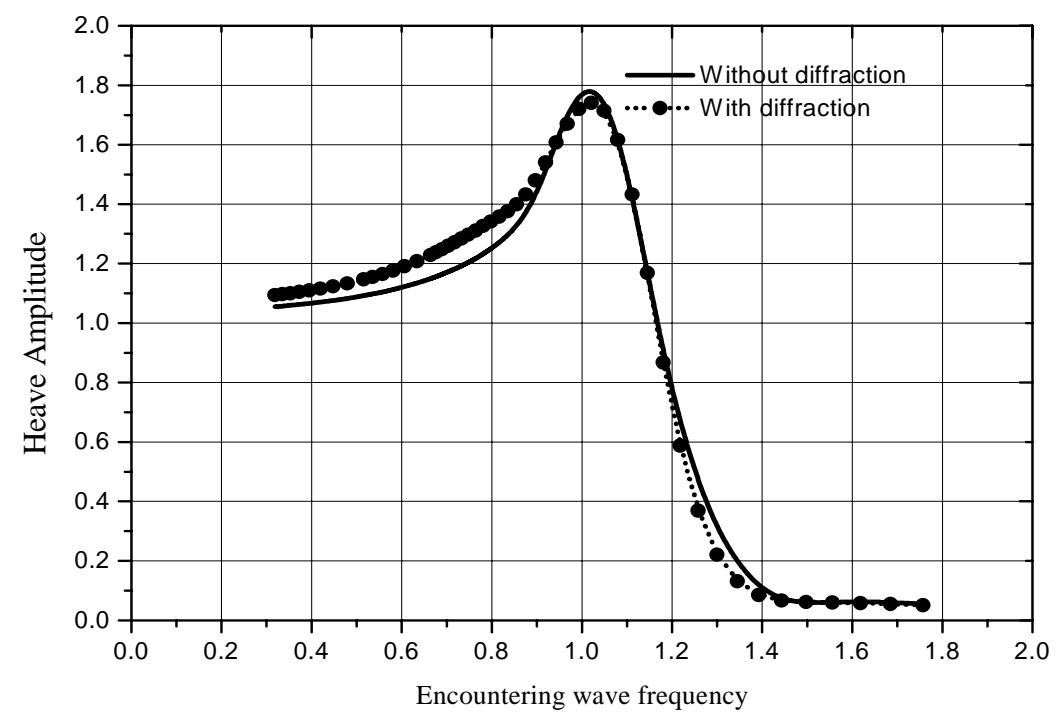

Figure 5: Comparison of Heave response with considering diffraction and without diffraction $\left(\mathrm{F}_{\mathrm{n}}=0.30\right.$, Series 60 of Block coefficient 0.6 , head sea condition)

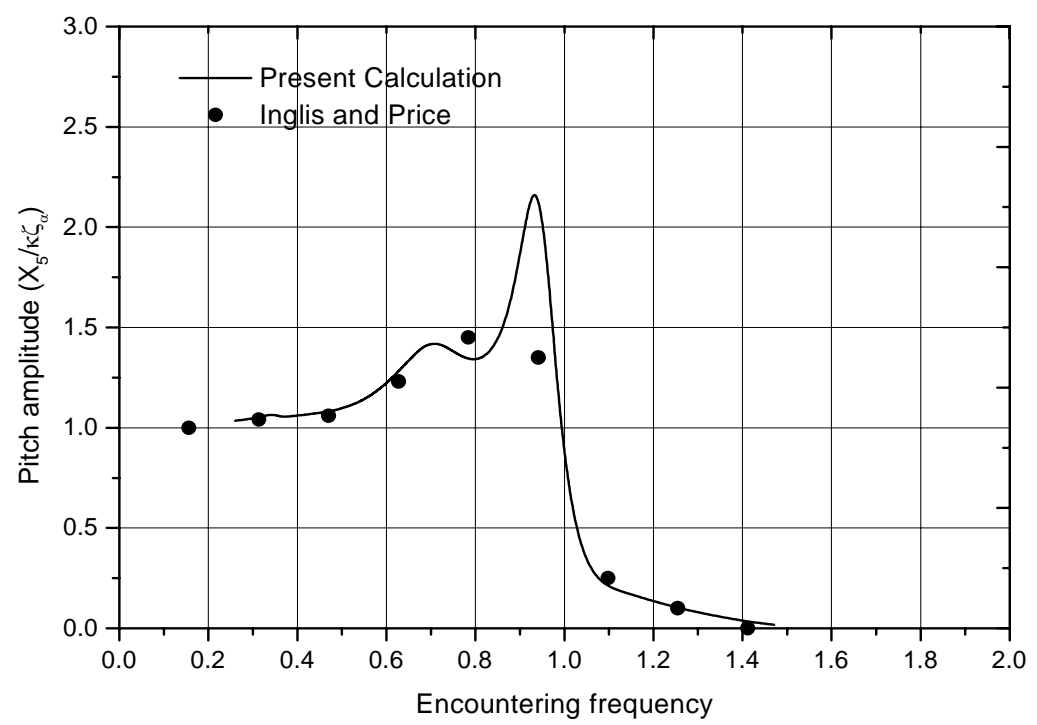

Figure 6: Comparison of Pitch responses $\left(\mathrm{F}_{\mathrm{n}}=0.20\right.$, Series 60 of Block coefficient 0.7 (head sea condition)

For maximum heave motion within the simulated time, it is seen from figure 7 that for Froude Number 0.25 with significant wave height $1.0 \mathrm{~m}$, relative stern rise above the wave surface, considering heave, pitch and wave $[\mathrm{a}+\mathrm{b}-( \pm \mathrm{c})]=+0.189+0.223-(-0.0616)$, where $\mathrm{a}, \mathrm{b}$ and $\mathrm{c}$ are defined in figure 13 , is 0.474 $\mathrm{m}$ and for maximum pitch condition $0.515 \mathrm{~m}$. From figure 8 with significant wave height $3.0 \mathrm{~m}$, the corresponding values are 1.47 and $1.554 \mathrm{~m}$ respectively.

Similarly, for maximum heave motion within the simulated time, it is seen from figure 9 that for Froude Number 0.40 with significant wave height 1.0, relative stern rise above the wave surface is $0.373 \mathrm{~m}$ and for maximum pitch condition $0.561 \mathrm{~m}$. From figure 10, with significant wave height 3.0 $\mathrm{m}$, the corresponding values are $1.008 \mathrm{~m}$ and $1.1027 \mathrm{~m}$ respectively. 
Again for maximum heave motion within the simulated time, it is seen from figure 11, that for Froude Number 0.50 with significant wave height $1.0 \mathrm{~m}$, relative stern rise above the wave surface is $0.187 \mathrm{~m}$ and for maximum pitch condition $0.430 \mathrm{~m}$. It is also seen from figure 10 that for significant wave height $3.0 \mathrm{~m}$, the corresponding values are $1.174 \mathrm{~m}$ and $1.196 \mathrm{~m}$ respectively.

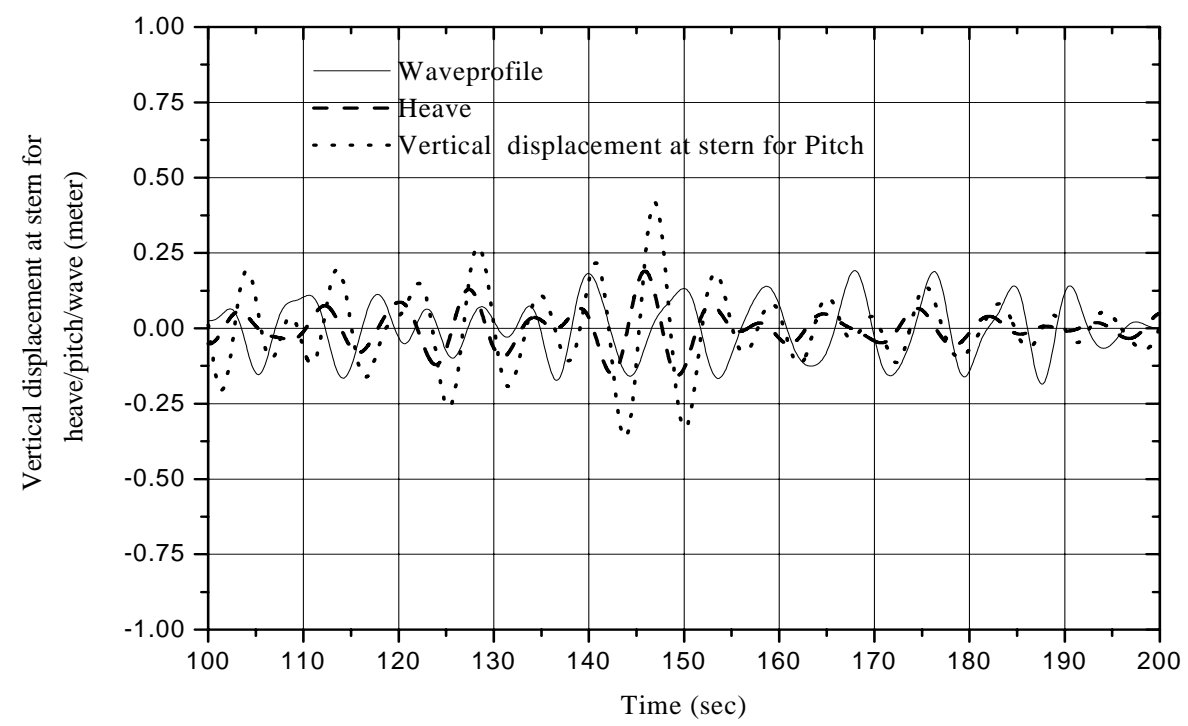

Figure 7: Comparison of heave motion and vertical displacement at stern due to pitch with wave elevation $(\mathrm{Fn}=0.25, \mathrm{SWH}=1.0 \mathrm{~m})$

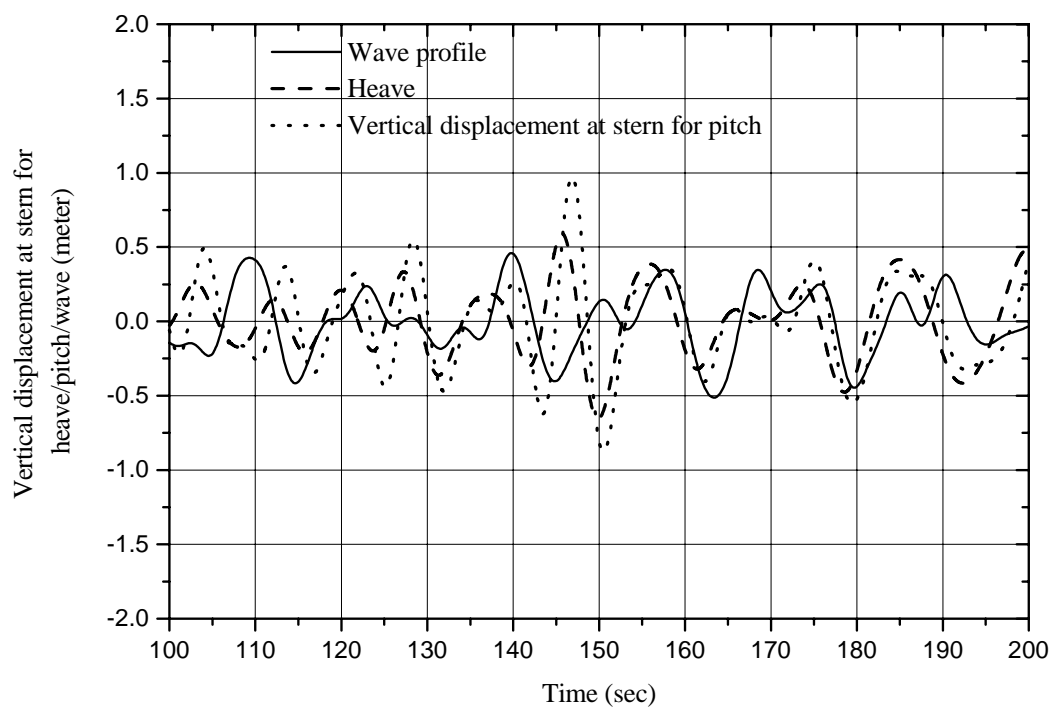

Figure 8: Comparison of heave motion and vertical displacement at stern due to pitch with wave elevation $(\mathrm{Fn}=0.25$, $\mathrm{SWH}=3.0 \mathrm{~m})$ 


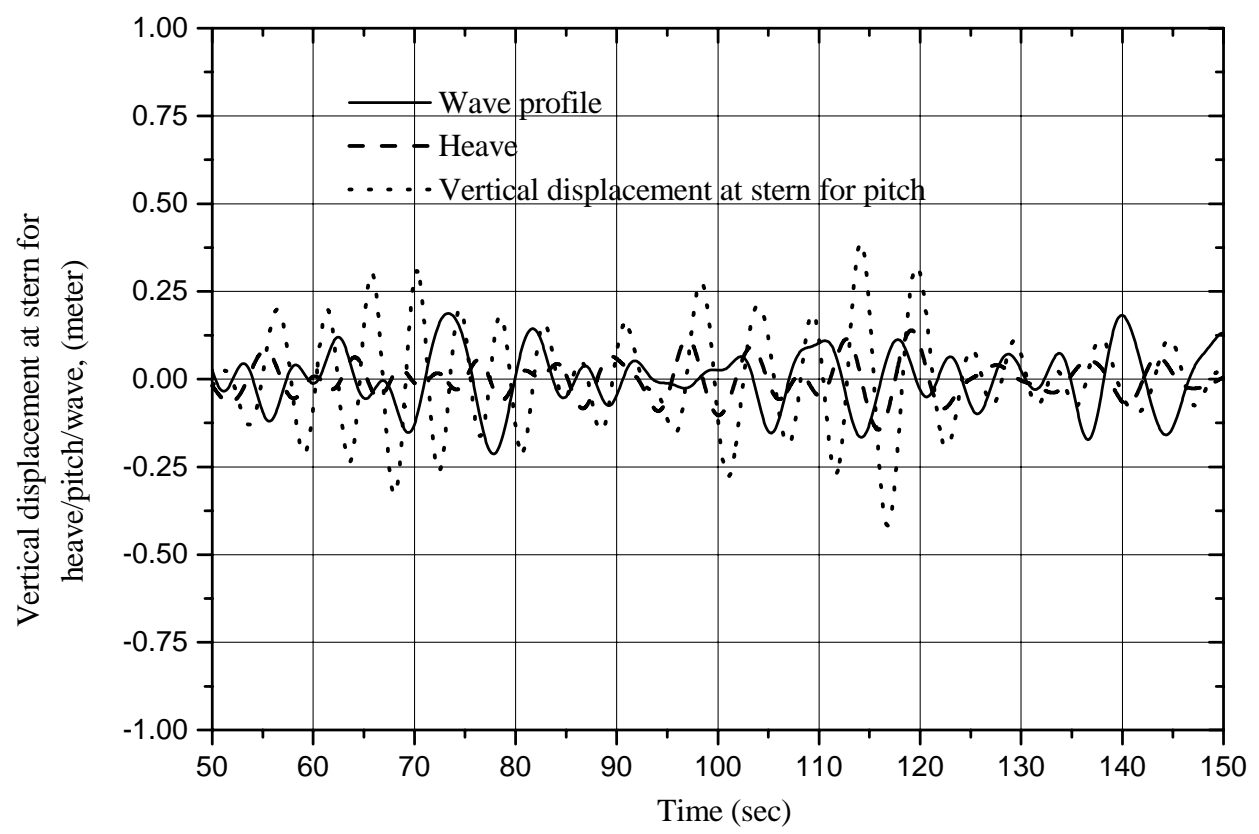

Figure 9: Comparison of heave motion and vertical displacement at stern due to pitch with wave elevation $(\mathrm{Fn}=0.40, \mathrm{SWH}=1 \mathrm{~m})$

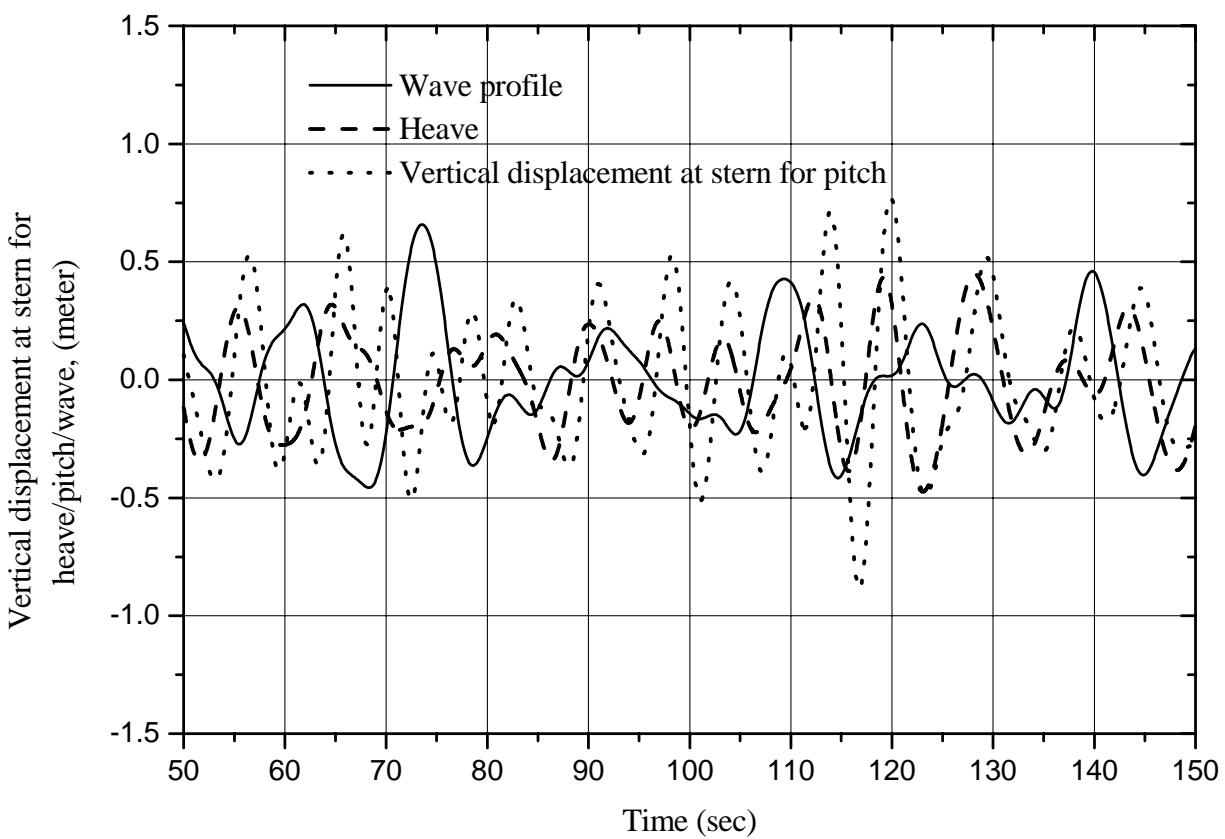

Figure 10: Comparison of heave motion and vertical displacement at stern due to pitch with wave elevation $(\mathrm{Fn}=0.40, \mathrm{SWH}=3 \mathrm{~m})$ 


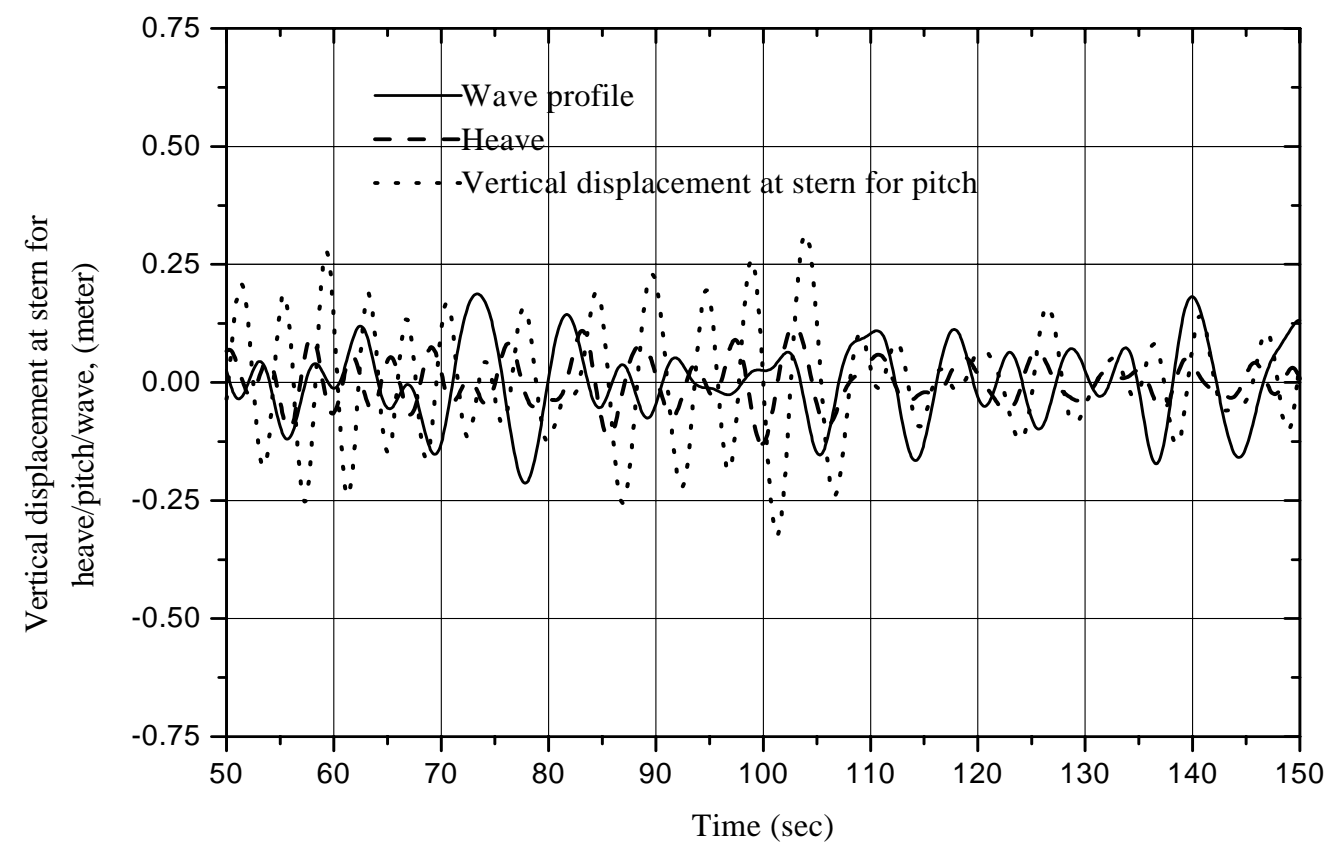

Figure 11: Comparison of heave motion and vertical displacement at stern due to pitch with wave elevation $(\mathrm{Fn}=0.50, \mathrm{SWH}=1 \mathrm{~m})$

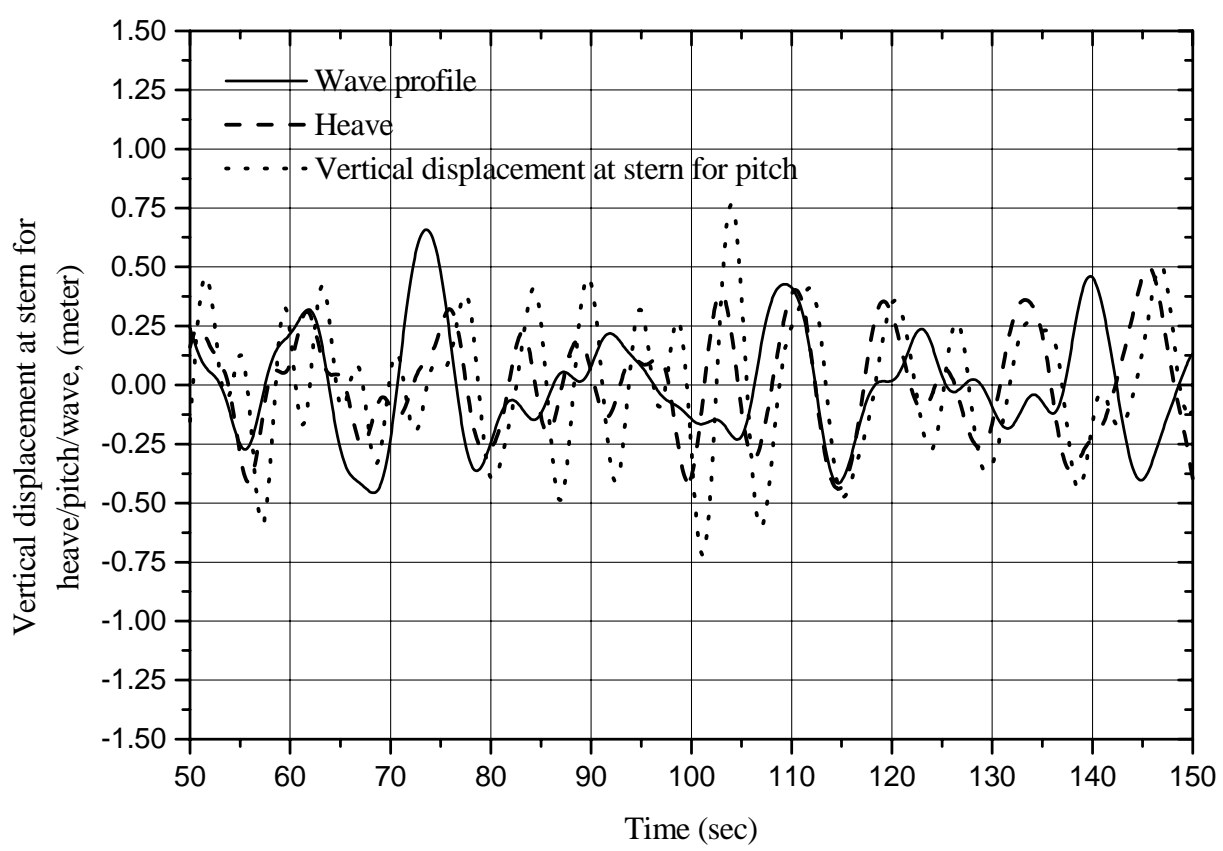

Figure 12: Comparison of heave motion and vertical displacement at stern due to pitch with wave elevation $(\mathrm{Fn}=0.50, \mathrm{SWH}=3 \mathrm{~m})$ 


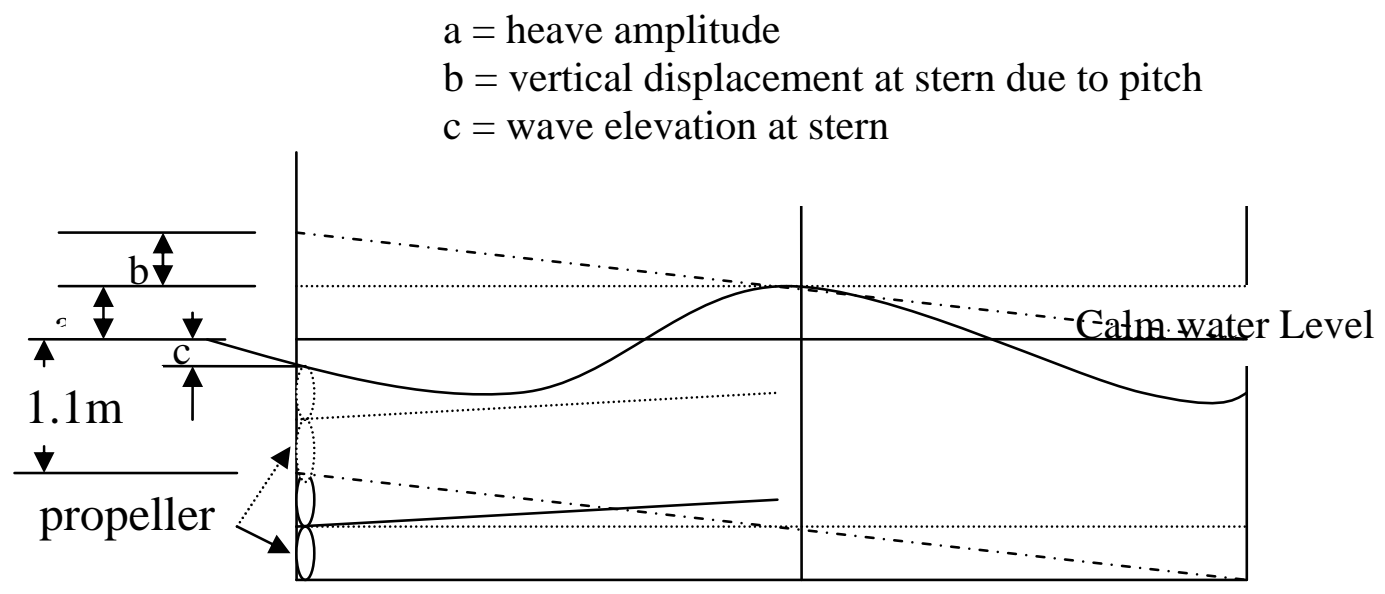

Figure 13: A typical sketches for relative rise of stern above wave surface

From these figures, it is also observed that maximum heave; maximum pitch and wave crest/trough are not coinciding at a point simultaneously. It may be noted that the propeller tip clearance from calm water level is $1.10 \mathrm{~m}$. Their combined effects are added according to Figure 13 to get total vertical displacement of a point relative to wave surface at stern position, which was initially on the load water line in calm water condition.

Considering this, it is seen from these three displacements that the ship can run smoothly for Froude Number up to 0.50 at significant wave height $1.0 \mathrm{~m}$ without any propeller emergence. Beyond this range there is a possibility of partial emergence of propeller once in the simulated time.

Table 2: Relative Vertical Displacement at stern

\begin{tabular}{|c|c|c|c|c|c|c|}
\hline Froude No. & $\begin{array}{l}\text { Significant } \\
\text { Wave } \\
\text { Height (m) }\end{array}$ & $\begin{array}{l}\text { Heave } \\
\text { amp., a } \\
\text { (m) }\end{array}$ & $\begin{array}{l}\text { Vertical } \\
\text { displacement } \\
\text { at stern due to } \\
\text { pitch, b (m) }\end{array}$ & $\begin{array}{l}\text { Wave } \\
\text { elevation, } \\
\text { c (m) }\end{array}$ & $\begin{array}{l}\text { Relative } \\
\text { vertical } \\
\text { displacement } \\
(\mathrm{a}+\mathrm{b}-\mathrm{c})(\mathrm{m})\end{array}$ & $\begin{array}{l}\text { Propeller } \\
\text { tip } \\
\text { emergence } \\
\text { (yes/No) }\end{array}$ \\
\hline \multirow{2}{*}{$\begin{array}{l}0.40 \\
\text { (Simulation } \\
\text { time at } 110 \\
\text { sec) }\end{array}$} & $1 \mathrm{~m}$ & -0.047 & 0.1119 & 0.10344 & -0.03854 & No \\
\hline & $3 \mathrm{~m}$ & 0.047 & 0.0664 & 0.41249 & -0.29909 & No \\
\hline $\begin{array}{l}0.50 \\
\text { (Simulation } \\
\text { time at } 104 \\
\text { sec) }\end{array}$ & $3 \mathrm{~m}$ & 0.2466 & 0.76089 & -0.21304 & 1.22053 & $\begin{array}{c}\text { Partial } \\
\text { Emergence }\end{array}$ \\
\hline
\end{tabular}

\section{Conclusions}

This particular research mainly focuses on the motion simulation of an existing fast fine vessel at Hiron point of the Bay of Bengal. For this purpose, a mathematical model based on 3-D source distribution has been developed and successfully utilized for calculation of the hydrodynamic coefficients and wave exciting forces in regular waves that are used as transfer functions for the program developed in time domain. A new wave spectrum formula at Hiron point of the Bay of Bengal has been used at various combination of significant wave height and ship speed. It may be noted that the results plotted are only for head sea condition (irregular unidirectional waves). 
On the basis of the results and discussions, at the concerned location, the studied ship can run smoothly up to significant wave height of $1 \mathrm{~m}$ with speed up to 22.8 knots (Froude Number 0.50) if both heave, pitch and wave elevations are considered. Beyond this range, the combined effect may start bringing the propeller tip out of water once in the simulated time. Moreover, the results can be applied for prediction of resistance increase, speed loss at constant power for the said vessel. However, the model can also be applied for prediction of performance of other ships as well by using different wave spectrum. As these days, the understanding of the motion behavior of high speed vessels has increased considerably; the present study has clearly demonstrated the applicability of the developed model.

\section{References}

Alam, M. S. 2000. An Estimation of wave spectrum by applying Fast Fourier Transform. Journal of Institution of Engineers, Malaysia. Vol. 61 No. 2. pp. 7-15.

Cummins, W. E. 1962. The impulse response function and ship motions. Schiffechnik, Bd. pp. 101103.

Faltinsen, O. M. \& Michelsen, F. C. 1975. Motions of Large Structures in Waves at zero Froude Number. International Symposium on the Dynamics of Marine Vehicles and Structures in Waves, Mechanical Engineering, Published in London. pp. 99-114.

Faltinsen, O. and Zhao, R. 1991. Numerical Prediction of ship motions at high speed. Phil. Trans. Roy. Series 4.334. pp. 241-252.

Garrison, C. J. 1978. Hydrodynamic Loading of Large Offshore Structures. Three Dimensional Source Distribution methods, Numerical Methods in Offshore Engineering. pp. 87-140.

Hassan, M. 2003. Motion Simulation of Naval Vessel with Forward Speed in a Rough Sea. M. Sc. Thesis. BUET, 92 pp.

Hogben, N. and Standing R. G. 1975. Wave Loads on Large Bodies. International Symposium on the Dynamics of Marine Vehicles and Structures in Waves, Mechanical Engineering, Published in London. pp. 273-292.

Inglis, R. B. and Price, W. G. 1981. Calculation of the Velocity Potential of a Translating, Pulsating Source. Trans. RINA 122. pp. 163-175.

Inglis, R. B. and Price, W. G. 1981. A Three Dimensional Ship Motion Theory: Calculation of Wave Loading and Responses with Forward Speed. Trans. RINA. pp. 183-192.

Inglis, R. B. and Price, W. G. 1982. A Three Dimensional Ship Motion Theory-Comparison between Theoretical predictions and Experimental Data of the Hydrodynamic Coefficients with Forward Speed. Trans. RINA. 124. pp. 141-157.

Inoue, Y. and Seif, M. S. 1996. Dynamics of Multibody Floating System. SNAJ.

Islam, M. R., Baree, M. S. and Islam, M. N. 2003. Hydrodynamic forces with effect of forward speed on floating bodies by 3-D source method. International Congress on Sports Dynamics: Discovery and Application. pp. 261-269.

Islam, M. R. 2001. A study of motion and non-linear second order drift forces of multi-body floating bodies in waves. Doctor of Engineering thesis, Yokohama National University, Japan.

Iwashita, H. and Okhusu, M. 1989. Hydrodynamic forces on a ship moving at forward speed in waves. J.S.N.A. Japan, 166. pp. 87-109.

Newman, J. N.1978. The theory of ship motion. Advances in Applied Mechanics 18. pp. 221-283. Principles of Naval Architecture. Volume: III, Motion in waves and controllability, TSNAME 1988.

Salvesen, N., Tuck, E. O. and Faltinsen, O. 1970. Ship motions and sea loads. SNAME 78. pp. 250287.

Vugts, J. H. 1971. The hydrodynamic forces and ship motions in oblique waves. Research Center TNO for Shipbuilding, Delft Report No 150S.

Wang Chun-Tsung. 1999. Vertical Motions of Slender Bodies with Forward Speed. Proc. Natl. Sci. Counc. ROC (A). 23. pp. 31-44.

Y. Makino. 1997. The Influence of Forward Speed upon 3 Dimensional Hydrodynamic Forces. M.Sc Thesis submitted in the Department of Naval Architecture and Ocean Engineering, Yokohama National University. Japan. 